\begin{tabular}{|c|l|}
\hline Title & A heme degradation enzyme, HutZ, from Vibrio cholerae \\
\hline Author(s) & Uchida, Takeshi; Sekine, Y ukari; Matsui, Toshitaka; Ikeda Saito, Masao; Ishimori, Koichiro \\
\hline Citation & $\begin{array}{l}\text { Chemical Communications, 48(53), 6741-6743 } \\
\text { https://doi.org/10.1039/c2c31147j }\end{array}$ \\
\hline Issue Date & 2012-06 \\
\hline Doc URL & http://hdl.handle.net/2115/68577 \\
\hline Type & article (author version) \\
\hline Additional Information & There are other files related to this item in HUSCAP. Check the above URL. \\
\hline File Information & C2Cc31147J-HUSCAP.pdf \\
\hline
\end{tabular}

Instructions for use 


\title{
A Heme Degradation Enzyme, HutZ, from Vibrio cholerae
}

\author{
Takeshi Uchida $^{\text {a,b }}$, Yukari Sekine ${ }^{\mathrm{b}}$, Toshitaka Matsui ${ }^{\mathrm{c}}$, Masao Ikeda-Saito ${ }^{\mathrm{c}}$, and Koichiro Ishimori ${ }^{\mathrm{a}, \mathrm{b}}$ \\ Received (in $X X X, X X X)$ Xth $X X X X X X X X X 200 X$, Accepted Xth $X X X X X X X X X 200 X$ \\ DOI: $10.1039 / b 000000 x$
}

\begin{abstract}
${ }_{5}$ HutZ, one of the crucial proteins of the iron uptake system in Vibrio cholerae was purified, which binds to heme at a stoichiometry of $1: 1$. In the presence of ascorbic acid, the HutZ-bound heme degrades via the same intermediates observed in heme oxygenase, suggesting that HutZ works as a 10 heme degradation enzyme.
\end{abstract}

Almost all bacteria require iron for their survival. Although iron is the most abundant transition metal on earth, within human body, bacteria encounter an extremely low iron milieu, because the majority of iron is sequestered in iron- and heme-containing 15 proteins. ${ }^{1}$ Therefore, bacterial pathogens have developed a mechanism that facilitates uptake of heme iron into their organism. Vibrio cholerae, the intestinal pathogen that causes cholera, also has an absolute requirement for iron and obtains this element in the human host as well as in its environmental niches. 20 Based on the genome sequence, putative genes coding heme acquisition have been discerned and called as Hut (Heme utilization $)^{2}$. However, less is known about molecular mechanisms of this system. In this study we focus on HutZ, ${ }^{2,3}$ a putative heme degrading enzyme proposed by the sequence 25 similarity with Helicobacter pylori HugZ, which is recently established as a heme degradation enzyme despite low sequence similarity to mammalian heme oxygenase (HO). ${ }^{4}$ We have overexpressed and purified HutZ and characterized it as a hemedegrading protein.

30 The hutZ gene was amplified and cloned into $\mathrm{pET}-28 \mathrm{~b}$ vector and expressed in BL21(DE3). The expressed HutZ was purified as a heme-free form. After cleavage of the $\mathrm{His}_{6}$-tag, heme reconstitution, and size exclusion chromatography, only one band was observed by SDS-PAGE with an apparent molecular mass of 35 approximately $22 \mathrm{kDa}$ (Fig. S1(A), ESI $\dagger$ ), in agreement with calculated molecular mass for HutZ $(21 \mathrm{kDa})$. Analysis of the heme-HutZ complex by size exclusion chromatography indicates that the protein exists as a dimer $(42 \mathrm{kDa})$ (Fig. S1(B), ESI $\dagger$ ). When an aliquot of hemin solution was added to HutZ at $\mathrm{pH}$ 8.0, 40 the resultant solutions gave a Soret band at approximately $410 \mathrm{~nm}$, which is clearly distinguishable from the Soret band of free hemin $\left(\lambda_{\max } \sim 385 \mathrm{~nm}\right.$ ), suggesting that heme specifically binds to HutZ. Utilizing the difference of the Soret peak absorbance of free and HutZ-bound hemin, we determined the stoichiometry of 45 the heme binding to HutZ to be 1:1 by the titration plots as shown in Fig. 1 (inset). The dissociation constant for hemin to HutZ was $0.052 \pm 0.020 \mu \mathrm{M}$, which is significantly lower than that of 0.84 $\pm 0.2 \mu \mathrm{M}$ reported for $\mathrm{HO}-1,{ }^{5}$ indicating that heme binds tighter to HutZ than to HO-1.

50

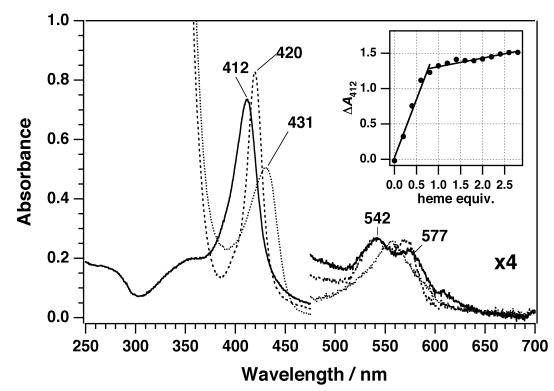

Fig. 1 Absorption spectra of the heme-HutZ complex. The protein concentration is $5 \mu \mathrm{M}$ (per heme basis) in $50 \mathrm{mM}$ Tris- $\mathrm{Cl} / 150 \mathrm{mM} \mathrm{NaCl}$, $\mathrm{pH}$ 8.0. Spectra shown are in the ferric (solid line), ferrous (dotted line), 55 and CO-bound forms (dashed line). (Inset) Heme-binding curve generated from the difference absorbance spectra by plotting $\Delta A_{412}$ vs. the molar ratios of hemin to the protein.

After incubation with free hemin followed by removal of excess hemin on a gel-filtration column, the protein showed the ${ }_{60}$ characteristic Soret absorption at $412 \mathrm{~nm}$ with the visible bands at 542 and $577 \mathrm{~nm}$ at $\mathrm{pH} 8.0$ (Fig. 1), which is almost identical to that reported before ${ }^{3}$. As a comparison of this spectrum to that of HO- 1 in the alkaline form, ${ }^{6}$ the ferric heme of heme-HutZ is predominantly in the 6-coordinate (6c) low spin (LS) state, and ${ }_{65}$ probably a hydroxide $\left(\mathrm{OH}^{-}\right)$ion is bound to the heme with histidine ligation. The absorption spectrum of ferric HutZ was sensitive to $\mathrm{pH}$. At acidic $\mathrm{pH}$, the spectrum exhibited a Soret maximum at $407 \mathrm{~nm}$ (Fig. S2, ESI $\dagger$ ), which progressively shifted to $412 \mathrm{~nm}$ with increasing $\mathrm{pH}$. The band at $630 \mathrm{~nm}$, which is 70 typically considered as a high spin (HS) marker, is present at $\mathrm{pH}$ 6 , but gradually disappeared as the $\mathrm{pH}$ was increased. These $\mathrm{pH}-$ dependent shifts are indicative of the equilibrium between HS $\left(\mathrm{Fe}^{3+}-\mathrm{H}_{2} \mathrm{O}\right)$ and $\mathrm{LS}\left(\mathrm{Fe}^{3+}-\mathrm{OH}^{-}\right)$species. Although the precise value was not determined due to instability of the protein below ${ }_{75} \mathrm{pH} \mathrm{6,} \mathrm{p} K_{\mathrm{a}}$ for the deprotonation of the coordinated water is below 7 (Fig. S2, inset, ESI $\dagger$ ). This equilibrium between HS and LS species would be attributed to a basic residue(s) within the distal pocket that might hydrogen bond to the heme-bound ligand, analogous to the distal histidine of globins. Although the crystal 80 structure of HutZ has not been solved, that of the homologous protein, HugZ, is available. ${ }^{7}$ That structure shows that Arg166 in HugZ is in a position to form a hydrogen bond to the iron-bound water through another water molecule (Fig. S3, ESI $\dagger$ ). As shown in the amino acid sequence alignment (Fig. S4, ESI $\uparrow$ ), the 
corresponding residue in HutZ is Arg92, which would be involved in the distal hydrogen-bonding network. When the heme iron was reduced by sodium dithionite, the Soret band appeared at $431 \mathrm{~nm}$ with a replacement of the distinct 542 and $577 \mathrm{~nm}$ ${ }_{5}$ peaks with a broad band at $530 \mathrm{~nm}$ (Fig. 1). These spectroscopic changes are indicative of 5 -coordinate $(5 \mathrm{c})$ heme as observed for deoxy myoglobin $(\mathrm{Mb}){ }^{8}$ Addition of carbon monoxide $(\mathrm{CO})$ to the reduced heme resulted in a shift of the Soret band to $420 \mathrm{~nm}$ (Fig. 1), which is also similar to that observed in CO-bound $\mathrm{Mb}$, 10 indicating that heme of the CO-bound HutZ has histidine as an axial heme ligand.

Resonance Raman (RR) spectra of HutZ for the ferric, ferrous and CO-bound forms are depicted in Fig. 2. It has been known that the spin-state marker band, $v_{3}$, is observed at $1480-1510 \mathrm{~cm}^{-1}$.

${ }_{15}^{9}$ For the ferric state of HutZ, the $v_{3}$ band was observed at 1503 $\mathrm{cm}^{-1}$ with a small band at $1474 \mathrm{~cm}^{-1}$, suggesting that ferric HutZ is a mixture of the $6 \mathrm{c}-\mathrm{LS}$ and $6 \mathrm{c}-\mathrm{HS}$ states, which is in agreement with the absorption spectrum (Fig. 1). For the ferrous form, the $v_{3}$ band appeared at $1468 \mathrm{~cm}^{-1}$, which is typical of the $5 \mathrm{c}-\mathrm{HS}$ heme. 20

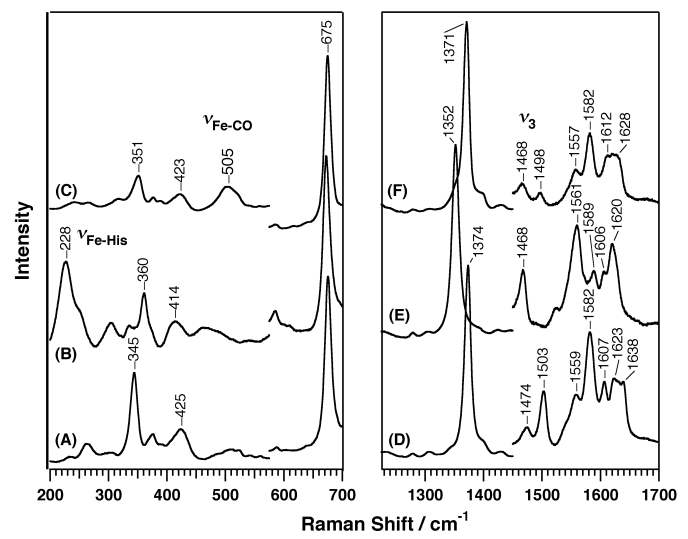

Fig. 2 RR spectra of the heme-HutZ complex in the low (left) and high frequency (right) regions. The protein concentration is $10 \mu \mathrm{M}$ in $50 \mathrm{mM}$ Tris-Cl, $\mathrm{pH}$ 8.0. Spectra shown are the ferric (A and D), ferrous (B and E), 25 and $\mathrm{CO}$-bound forms $(\mathrm{C}$ and $\mathrm{F})$. The excitation wavelength for ferric and CO-bound forms is $413.1 \mathrm{~nm}$, and that for ferrous form is $441.6 \mathrm{~nm}$.

We further measured RR spectrum of the CO-bound form. An isotope-sensitive band appeared at $505 \mathrm{~cm}^{-1}$, which was downshifted by $15 \mathrm{~cm}^{-1}$ upon ${ }^{13} \mathrm{C}^{18} \mathrm{O}$ isotope substitution, and assigned 30 to the $\mathrm{Fe}-\mathrm{CO}$ stretching mode $\left(v_{\mathrm{Fe}-\mathrm{CO}}\right)$. The frequency of $v_{\mathrm{Fe}-\mathrm{CO}}$ is sensitive to the nearby environment of the heme and thus can be used to explorer heme active site structure. ${ }^{10} \mathrm{In} \mathrm{Mb}$, the presence of a weak electrostatic interaction between the heme-bound $\mathrm{CO}$ and distal histidine leads to $v_{\mathrm{Fe}-\mathrm{CO}}$ at $507 \mathrm{~cm}^{-1}$, while removable 35 of this histidine results in a downshift to $490 \mathrm{~cm}^{-1} \cdot{ }^{10,11} v_{\mathrm{Fe}-\mathrm{CO}}$ of $505 \mathrm{~cm}^{-1}$ for HutZ is almost identical to those of Mb and HO-1 $\left(503 \mathrm{~cm}^{-1}\right){ }^{12}$ This frequency of $v_{\mathrm{Fe}-\mathrm{CO}}$ supports the abovementioned idea of hydrogen-bonding network in the distal site, by which the heme-bound $\mathrm{CO}$ is stabilized. In $\mathrm{HmuO}$, a bacterial $\mathrm{HO}$,

40 the crystal structure of the ferrous oxy form showed that ironbound $\mathrm{O}_{2}$ is hydrogen bonded with the amide nitrogen of the distal glycine and the nearby $\mathrm{H}_{2} \mathrm{O}$ molecule. ${ }^{13}$ In $\mathrm{HO}-1$, it has been proposed that the hydrogen-bonding network is designated for the proton transfer to the active site. ${ }^{14}$ The distal pocket 45 hydrogen-bonding network seen in HutZ is also likely to be essential for its heme degrading reaction.

Another CO isotope-sensitive band was observed at $1930 \mathrm{~cm}^{-1}$ (data not shown), which is assignable to the $\mathrm{C}-\mathrm{O}$ stretching mode ( $v_{\mathrm{C}-\mathrm{O}}$ ) due to the downshift by $90 \mathrm{~cm}^{-1}$ upon ${ }^{13} \mathrm{C}^{18} \mathrm{O}$-substitution. ${ }_{50}$ The frequencies of $v_{\mathrm{Fe}-\mathrm{CO}}$ and $v_{\mathrm{C}-\mathrm{O}}$ typically follow a well known inverse correlation (Fig. S5, ESI $\uparrow$ ). ${ }^{15,16}$ The inverse correlation line is sensitive to the proximal ligand, such that the line for histidine coordination species is distinct from that of thiolatecoordinated species. Interestingly, the data point of $v_{\mathrm{Fe}-\mathrm{CO}}$ and $v_{\mathrm{C}-}$

${ }_{55} \mathrm{O}$ for HutZ fell off far from the line for histidine coordination species, but near the thiolate-, and imidazolate-coordinated species. Although HutZ has one cysteine residue at 110 , the possibility of the Cys 110 coordination can be easily ruled out, because sequence alignment with HugZ shows that Cys110 is not ${ }_{60}$ conserved (Fig. S4, ESI $\dagger$ ) and is located far from the heme binding site. ${ }^{7}$ Furthermore, absorption spectra suggest the histidine rather than cysteine coordination (Fig. 1). The proximal histidine for HugZ is His245 and the corresponding residue in HutZ is His170 (Fig. S4, ESI†). If His170 of HutZ is the axial ${ }_{65}$ ligand of heme, the correlation plot suggests that this histidine should have an anionic imidazolate character.

To confirm the status of the iron-coordinated histidine, we tried to observe the Fe-His stretching mode $\left(v_{\mathrm{Fe}-\mathrm{His}}\right)$, which is generally observed at $200-250 \mathrm{~cm}^{-1}$ for the ferrous heme 70 containing a 5c-HS heme. ${ }^{17,18}$ Fig. 2 (spectra B, E) shows the RR spectra for the dithionite-reduced HutZ with excitation at 441.6 $\mathrm{nm}$. An intense band was observed at $228 \mathrm{~cm}^{-1}$, which is assignable to the $\mathrm{Fe}-\mathrm{His}$ stretching mode. The $v_{\mathrm{Fe}-\mathrm{His}}$ frequency of HutZ is higher than that of HO-1 $\left(216\right.$, or $\left.218 \mathrm{~cm}^{-1}\right) .{ }^{12,19}$ The $v_{\mathrm{Fe}-}$ $75 \mathrm{His}$ frequency reflects mainly the hydrogen-bonding status of $\mathrm{N}_{t}-\mathrm{H}$ of the coordinated histidine. ${ }^{20}$ Therefore, the $v_{\mathrm{Fe}-\mathrm{His}}$ frequency of HutZ suggests that hydrogen bonding with proximal His in HutZ is stronger than that in HO-1. A closer look at the crystal structure of HugZ revealed that heme ligand histidine is within 80 hydrogen-bonding distance to Asp207, ${ }^{7}$ which is conserved in HutZ. The corresponding residue in HutZ is Asp132, which would enhance the imidazolate character of the proximal histidine.

We next evaluated an ability of HutZ to degrade heme under single turnover conditions. To the solution of heme-bound HutZ 85 was added ascorbic acid with monitoring spectral changes between 250 and $800 \mathrm{~nm}$. The reaction resulted in a loss of the absorbance of the Soret band (Fig. 3), and appearance of broad featureless absorption in the visible region. This spectral change is typical for the formation of a ferric-biliverdin complex, a heme 90 degradation product of mammalian $\mathrm{HO}$ using ascorbate as a reductant. ${ }^{21}$ Such spectral changes did not occurr without HutZ (data not shown). These results indicate that HutZ is an enzyme capable for degradation of heme.

Heme degradation mechanism by $\mathrm{HO}$ has been established ${ }_{95}$ (Fig. S6, ESI $\dagger$ ). ${ }^{22}$ The initial reduction of the ferric heme iron allows rapid $\mathrm{O}_{2}$-binding. Subsequent one-electron reduction of the oxy form $\left(\mathrm{Fe}^{2+}-\mathrm{O}_{2}\right)$ generates the ferric hydroperoxy species $\left(\mathrm{Fe}^{3+}-\mathrm{OOH}\right)$, which self-hydroxylates the heme to yield $\alpha$-mesohydroxyheme (Fig. S6 (e), ESI $\dagger$ ). Hence, we first tried to trap the 100 oxy form of heme-bound HutZ. Ferric heme-HutZ was reduced by sodium dithionite and gel-filtrated in an anaerobic glove box. Then, an approximately equimolar amount of oxygen was added to the reductant-free ferrous HutZ solution. Even immediate after 
the addition of oxygen to the ferrous HutZ (approximately $10 \mathrm{~s}$ ), the observed UV-vis spectrum was characteristic of ferric HutZ. Considering that the oxy form of rat HO- 1 is highly stable $\left(t_{1 / 2} \sim\right.$ $1.4 \mathrm{~h}),{ }^{23}$ that of HutZ is highly susceptible to autooxidation.

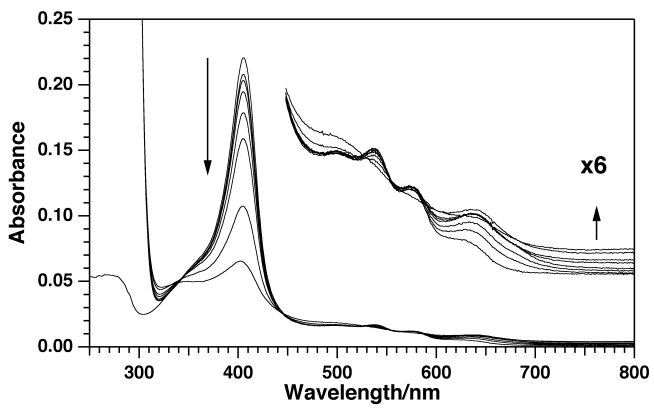

Fig. 3 Reaction of HutZ with ascorbic acid. The spectra were taken before and at $0.5,1,2,3,5$, and $7 \mathrm{~min}$ after addition of ascorbic acid (1 $\mathrm{mM})$ to ferric heme-HutZ $(2 \mu \mathrm{M})$ in $50 \mathrm{mM}$ MES, $\mathrm{pH} 6.0$ at $25{ }^{\circ} \mathrm{C}$. The 10 progression of the spectra is indicated by the arrows.

We next examined reaction of ferric heme-HutZ with $\mathrm{H}_{2} \mathrm{O}_{2}$. $\mathrm{H}_{2} \mathrm{O}_{2}$ as a surrogate of oxygen and two electrons supports the heme hydroxylation by mammalian $\mathrm{HO}$ to accumulate ferric verdoheme because of rapid oxidation of meso-hydroxyheme in 15 the presence of oxygen (Fig. S6 $(\mathrm{e}, \mathrm{f}), \mathrm{ESI} \dagger){ }^{24}$ The $\mathrm{H}_{2} \mathrm{O}_{2}$ reaction of HutZ resulted in a significant decrease in the Soret band and concomitant increase in the absorption around $644 \mathrm{~nm}$ (Fig. S7, ESI $\dagger$ ). This spectral change strongly suggests the formation of a verdoheme intermediate. Pyridine adduct of the reaction product 20 also exhibited an absorption spectrum typical of a pyridineverdohemochrome (Fig. S8, ESI $\dagger$ ). Absorption maximum of the HutZ-verdohemochrome $(659 \mathrm{~nm})$ is close to that of $\beta$-, or $\delta$ isomer among four regioisomers of the pyridineverdohemochrome $(680,663,648$ and $660 \mathrm{~nm}$ for $\alpha-, \beta-, \gamma$ - and ${ }_{25} \delta$-isomers, respectively), ${ }^{25}$ suggesting ring-cleavage at the $\beta$-, or $\delta$-meso-position. While most of the HO-1 enzymes degrade heme to $\alpha$-biliverdin, ${ }^{13}$ the $\mathrm{HO}$ from Pseudomonas aeruginosa is reported to cleave the macrocycle at the $\beta$ - or $\delta$-meso position. ${ }^{26}$

In the $\mathrm{HO}$ catalysis, reduction of ferric verdoheme initiates the 30 final $\mathrm{O}_{2}$ reaction that leads to formation of ferric-biliverdin and biliverdin (Fig. S6 (f-i), ESI†). Aerobic addition of ascorbic acid to the verdoheme-HutZ solution caused a Soret shift to $380 \mathrm{~nm}$ and disappearance of the sharp $644 \mathrm{~nm}$ band (Fig. S7, ESI $\dagger$ ). Since the resulting broad featureless absorption from 500 to 800 ${ }_{35} \mathrm{~nm}$ is again typical for the ferric-biliverdin complex, ${ }^{21}$ it is highly likely that the verdoheme is a reactive intermediate of the HutZ catalysis.

In summary, HutZ from $V$. cholerae was found to function as a heme-degrading enzyme. The heme degradation by HutZ appears 40 to proceed through a mechanism similar to that of HO including the meso-hydroxylation of heme and the ring opening of the verdoheme intermediate. Only the exception seems to be the plausible $\beta$-, or $\delta$-regioselectivity of HutZ, and further product analysis is underway.

45 This work was supported by Grant-in-Aid for Scientific Research (24550182 to T.U., 23550186 to T.M., 24350081 to M. I.-S., and 21370040 to K.I.,) and for the Global COE Program (Project No. B01 for T.U.), and performed under the Cooperative
Research Program of "Network Joint Research Center for ${ }_{50}$ Materials and Devices" of MEXT, Japan.

\section{Notes and references}

${ }^{a}$ Department of Chemistry, Faculty of Science, Hokkaido University, Sapporo 060-0810, Japan. Fax: +81 11706 3501; Tel: +81706 3506 Email:uchida@sci.hokudai.ac.jp

${ }_{55}{ }^{b}$ Graduate School of Chemical Sciences and Engineering, Hokkaido University, Sapporo, 060-0810, Japan

${ }^{c}$ Institute of Multidisciplinary Research for Advanced Materials, Tohoku University, Katahira, Sendai, 980-8577, Japan

$\dagger$ Electronic Supplementary Information (ESI) available: [details of any 60 supplementary information available should be included here]. See DOI: $10.1039 / \mathrm{b} 000000 \mathrm{x} /$

1. B. R. Otto, A. M. Verweij-van Vught and D. M. MacLaren, Crit. Rev. Microbiol., 1992, 18, 217.

65 2. E. E. Wyckoff, A. R. Mey and S. M. Payne, Biometals, 2007, 20, 405.

3. E. E. Wyckoff, M. Schmitt, A. Wilks and S. M. Payne, J. Bacteriol., 2004, 186, 4142 .

4. Y. Guo, G. Guo, X. H. Mao, W. J. Zhang, J. Xiao, W. D. Tong, T. Liu, B. Xiao, X. F. Liu, Y. J. Feng and Q. M. Zou, Bmc Microbiology, $2008,8,226$.

5. A. Wilks, P. R. Ortiz de Montellano, J. Sun and T. M. Loehr, Biochemistry, 1996, 35, 930.

6. S. Takahashi, J. Wang, D. L. Rousseau, K. Ishikawa, T. Yoshida, J. R. Host and M. Ikeda-Saito, J. Biol. Chem., 1994, 269, 1010.

75 7. Y. Hu, F. Jiang, Y. Guo, X. Shen, Y. Zhang, R. Zhang, G. Guo, X. Mao, Q. Zou and D. C. Wang, J. Biol. Chem., 2011, 286, 1537.

8. E. Antonini and M. Brunori, Hemoglobin and Myoglobin in Their Reactions with Ligands, North Holland Publishing Co., Amsterdam, 1971.

80 9. T. G. Spiro, J. D. Stong and P. Stein, J. Am. Chem. Soc., 1979, 101, 2648; T. G. Spiro and X.-Y. Li, in Biological Applications of Raman Spectroscopy, ed T. G. Spiro, John Wiley \& Sons, New York, 1988, vol. 3, pp. 1-37.

10. G. B. Ray, X. Y. Li, J. A. Ibers, J. L. Sessler and T. G. Spiro, J. Am. Chem. Soc., 1994, 116, 162.

11. J. Ramsden and T. G. Spiro, Biochemistry, 1989, 28, 3125.

12. S. Takahashi, J. Wang, D. L. Rousseau, K. Ishikawa, T. Yoshida, N. Takeuchi and M. Ikeda-Saito, Biochemistry, 1994, 33, 5531.

13. M. Unno, T. Matsui, G. C. Chu, M. Couture, T. Yoshida, D. L. Rousseau, J. S. Olson and M. Ikeda-Saito, J. Biol. Chem., 2004, 279, 21055.

14. R. Davydov, V. Kofman, H. Fujii, T. Yoshida, M. Ikeda-Saito and B. M. Hoffman, J. Am. Chem. Soc., 2002, 124, 1798.

15. N.-T. Yu and E. A. Kerr, in Biological Applications of Raman Spectroscopy, ed T. G. Spiro, John Wiley \& Sons, New York, 1988, vol. 3, pp. 39-95.

16. T. G. Spiro and I. H. Wasbotten, J. Inorg. Biochem., 2005, 99, 34.

17. T. Kitagawa, K. Nagai and M. Tsubaki, FEBS Lett., 1979, 104, 376.

18. J. Kincaid, P. Stein and T. G. Spiro, Proc. Natl. Acad. Sci. U.S.A., $1979,76,549$.

19. J. Sun, T. M. Loehr, A. Wilks and P. R. Ortiz de Montellano, Biochemistry, 1994, 33, 13734.

20. T. Kitagawa, in Biological Applications of Raman Spectroscopy, ed T. G. Spiro, John Wiley \& Sons, New York, 1988, vol. 3, pp. 97-131.

105 21. Y. Liu and P. R. Ortiz de Montellano, J. Biol. Chem., 2000, 275, 5297.

22. P. R. Ortiz de Montellano, Acc. Chem. Res., 1998, 31, 543; M. Unno, T. Matsui and M. Ikeda-Saito, Nat. Prod. Rep., 2007, 24, 553.

23. H. Fujii, X. Zhang, T. Tomita, M. Ikeda-Saito and T. Yoshida, J. Am. Chem. Soc., 2001, 123, 6475.

24. A. Wilks and P. R. Ortiz de Montellano, J. Biol. Chem., 1993, 268, 22357.

25. H. Sakamoto, Y. Omata, Y. Adachi, G. Palmer and M. Noguchi, J. Inorg. Biochem., 2000, 82, 113.

115 26. M. Ratliff, W. Zhu, R. Deshmukh, A. Wilks and I. Stojiljkovic, J. Bacteriol., 2001, 183, 6394. 